\title{
A STUDY OF CLASSIFICATION CRITERIA FOR A DIAGNOSIS OF JUVENILE RHEUMATOID ARTHRITIS
}

\author{
J. T. CASSIDY, J. E. LEVINSON, J. C. BASS, J. BAUM, E. J. BREWER, JR., C. W. FINK, V. HANSON, \\ J. C. JACOBS, A. T. MASI, J. G. SCHALLER, J. F. FRIES, D. McSHANE, and D. YOUNG
}

Criteria for the classification of juvenile rheumatoid arthritis were analyzed in a detailed database of $\mathbf{2 5 0}$ children in order to assess the accuracy of diagnosis and validity of onset types and course subtypes. A number of conclusions have been derived from this study: 1) All definitions of the 1973 criteria for classification of juvenile rheumatoid arthritis should be retained. 2) The addition of onset types to the 1976 revision of the criteria has been validated. 3) The course of the disease after the onset period of 6 months is as important to the outcome of a group of children as is the onset type. 4) The current classification should be broadened to include the course subtypes.

In 1963, Dr. Marian Ropes, President of the American Rheumatism Association (ARA), appointed a committee to study classification criteria for juvenile

From the Subcommittee on Classification Criteria for a Diagnosis of Juvenile Rheumatoid Arthritis, a subcommittee of the Diagnostic and Therapeutic Criteria Committee of the American Rheumatism Association.

J. T. Cassidy, MD: University of Michigan, Ann Arbor, MI; J. E. Levinson, MD: University of Cincinnati, Cincinnati, OH; J. C. Bass, MD: Ohio State University, Columbus, OH; J. Baum, MD: University of Rochester, Rochester, NY; E. J. Brewer, Jr., MD: Baylor University, Houston, TX; C. W. Fink, MD: Southwestern University, Dallas, TX; V. Hanson, MD: University of Southern California, Los Angeles, CA; J. C. Jacobs, MD: Columbia University, New York, NY; A. T. Masi, MD: University of Illinois, Peoria, IL; J. G. Schaller, MD: Tufts University, Boston, MA; J. F. Fries, MD: Stanford University, Stanford, CA; D. McShane, MD: Stanford University, Stanford, CA; D. Young, PhD: Stanford University, Stanford, CA.

Address reprint requests to the American Rheumatism Association, 17 Executive Park Drive NE, Suite 480, Atlanta, GA 30329, or to James T. Cassidy, MD, Department of Pediatrics, Suite 6820 , Creighton University School of Medicine, 601 North 30th Street, Omaha, NE 68131.

Submitted for publication December 6, 1984; accepted in revised form June 19, 1985 . rheumatoid arthritis. A set of criteria, including a long list of diagnostic exclusions, was developed on the basis of clinical experience, and it was determined that the term juvenile rheumatoid arthritis (JRA) should be restricted to chronic arthritis developing in children younger than age 16, and should be based on demonstration of objective signs of inflammatory joint involvement. These criteria were subsequently evaluated both in retrospective and in prospective studies (1). Modifications of the original criteria were developed in 1976, to place greater emphasis on the 3 onset types that had been identified (2).

The present study, by the Subcommittee on Classification Criteria for a Diagnosis of Juvenile Rheumatoid Arthritis, a subcommittee of the Diagnostic and Therapeutic Criteria Committee of the ARA, was begun in 1977 to evaluate these onset types. The subcommittee used the computerized database that had been meticulously compiled over many years by Dr. Joseph Levinson and his associates at the University of Cincinnati. In this report, we review the results of this study of onset types and course subtypes in children with JRA. Although extensive analyses were done, only those results specifically addressing classification are presented.

\section{PATIENTS AND METHODS}

Children diagnosed as having JRA met the classification criteria established in 1976 (2). All children referred to the University of Cincinnati between 1958 and 1978, who satisfied the entry criteria were enrolled in the study. The characteristics of the Cincinnati study group are shown in Table 1 . The study entry times were not controlled by any predetermined design except for the point at which the child was referred to the unit for evaluation; the point of exit from 
Table 1. Characteristics of the Cincinnati database study group*

\begin{tabular}{lr}
\hline \multicolumn{1}{c}{ Characteristic } & $\mathrm{n}$ \\
\hline Total number of children & 546 \\
Definite JRA & 250 \\
Polyarthritis onset & 78 \\
Early entry & 42 \\
Late entry & 36 \\
Oligoarthritis onset & 121 \\
Early entry & 59 \\
Late entry & 62 \\
Systemic onset & 51 \\
Early entry & 28 \\
Late entry & 23 \\
Possible or probable JRA & 223 \\
Other connective tissue diseases & 73 \\
\hline
\end{tabular}

* JRA = juvenile rheumatoid arthritis; early entry = entry into the study during the first 6 months of disease; late entry = entry into the study after the first 6 months of disease; possible JRA $=$ history of arthritis, but objective arthritis not documented by physician entering the child into the study; probable JRA = objective arthritis of less than 6 weeks duration.

the study was subject to the usual biases of referral patterns and the mobility of the child's parents. All data for the study were entered prospectively, on standardized forms. Children examined at Cincinnati within the first 6 months after disease onset were classified as the early-entry group, and children entered into the study after this period of time were the late-entry group. For the latter group of children, the characteristics of the onset period were determined from their medical records.

The children were reexamined at 6-month intervals throughout the study period. Routine laboratory tests required according to the clinical status of the child were performed at each visit, along with ophthalmologic examinations. Conventional radiologic films of affected joints were obtained at disease onset and then every 2 years thereafter. Fluorescent antinuclear antibody (ANA) preparations used cryostat sections of human thyroid as substrate (positive $>1: 10$ ). Rheumatoid factors were determined by a slide latex test (Hyland, Costa Mesa, CA) and confirmed by the RoseWaaler sensitized sheep cell agglutination test (SCAT; positive >1:4). All data were entered into the ARA Medical Information System (ARAMIS) at Stanford University and were analyzed by standard statistical programs.

The early-entry versus late-entry groups were extensively analyzed based upon previously identified segregating factors. Numerous comparisons were also made among the 3 onset types regarding key variables such as SCAT positivity, ANA positivity, HLA-B27 positivity, development of uveitis, remission before or after 5 years, and development of erosions; standard variables of age at disease onset, cumulative number of inflamed joints, and number of inflamed joints counted at each visit; and sex. The subsequent course of each child was also analyzed according to the following: (a) those with systemic onset disease which developed into a polyarthric course versus into an oligoarthric or pauciarticular course; (b) those with systemic onset disease and a polyarthric course versus those who had a polyarthric onset; and (c) those with oligoarthritis at disease onset with subsequent monarthric, oligoarthric, or polyarthric courses.

\section{RESULTS}

Early-entry versus late-entry group. An extensive comparison of the early-versus late-entry groups for each of the 3 onset types was performed. No significant differences were identified between the early- and late-entry groups for any onset type. Thus, these 2 groups of children were combined for all subsequent analyses.

SCAT, ANA, and HLA-B27 positivity. Figure 1 shows the number of children in each of the 3 onset groups, segregated by results of tests for SCAT, ANA, and HLA-B27 type. The small numbers in certain groups made statistical analyses impossible for many of the associations. For example, there was only 1 child who had oligoarthritis and had positive results on SCAT, ANA, and B27 determinations.

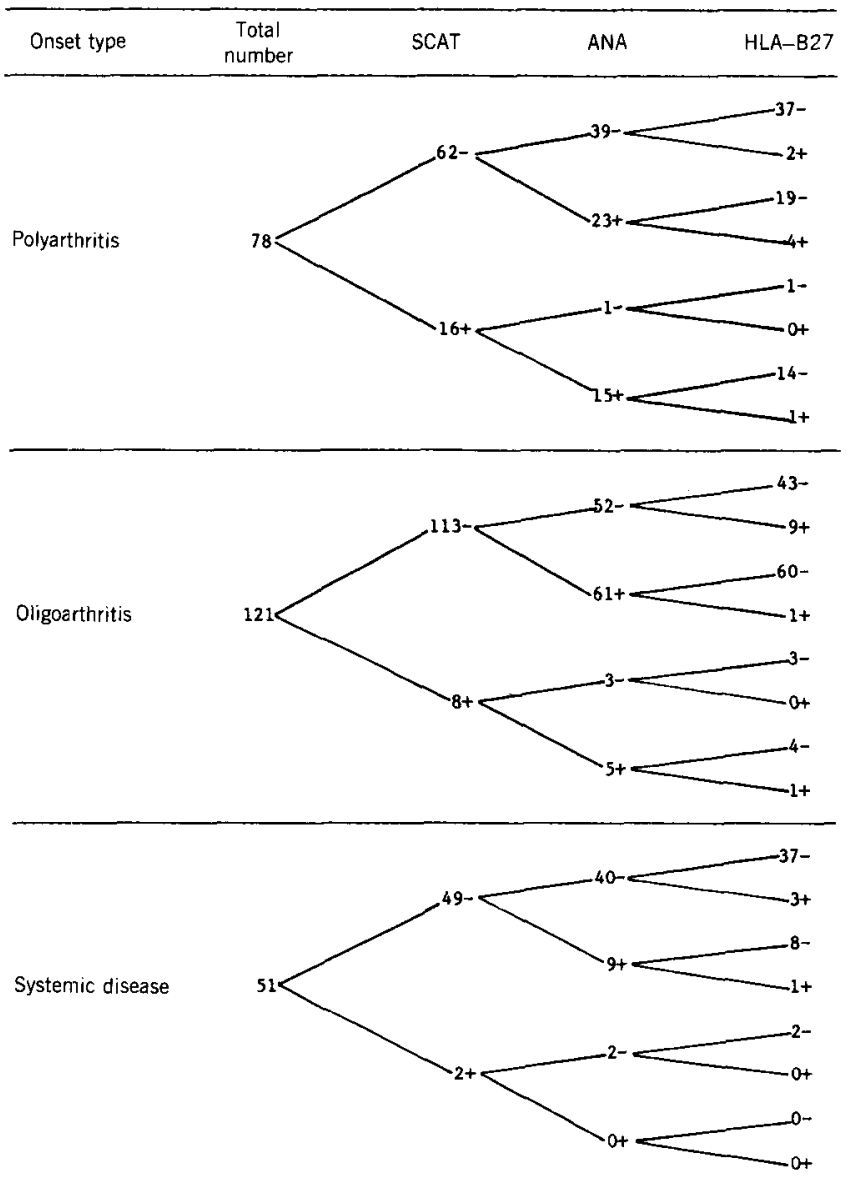

Figure 1. Frequencies of positive or negative results on sheep cell agglutination test (SCAT), antinuclear antibody test (ANA), and typing for HLA-B27, according to disease onset type. 
Table 2. Characteristics of children with juvenile rheumatoid arthritis, according to disease onset type and disease duration

\begin{tabular}{|c|c|c|c|c|c|c|c|c|c|c|c|c|c|c|c|}
\hline & \multicolumn{5}{|c|}{$\begin{array}{c}\text { Polyarthritis } \\
\text { followup at (years) }\end{array}$} & \multicolumn{5}{|c|}{$\begin{array}{c}\text { Oligoarthritis } \\
\text { followup at (years) }\end{array}$} & \multicolumn{5}{|c|}{$\begin{array}{l}\text { Systemic disease } \\
\text { followup at (years) }\end{array}$} \\
\hline & $1 / 2$ & 3 & 5 & 7 & 10 & $1 / 2$ & 3 & 5 & 7 & 10 & $1 / 2$ & 3 & 5 & 7 & 10 \\
\hline No. of children & 41 & 51 & 46 & 37 & 23 & 64 & 79 & 65 & 47 & 34 & 26 & 26 & 21 & 18 & 15 \\
\hline$\%$ male & 20 & 22 & 28 & 22 & 17 & 37 & 30 & 26 & 28 & 18 & 27 & 27 & 33 & 33 & 47 \\
\hline $\begin{array}{l}\text { Age at disease onset } \\
\text { (years, mean) }\end{array}$ & 8.3 & 8.5 & 8.7 & 8.3 & 7.2 & 6.5 & 6.7 & 6.8 & 6.0 & 5.6 & 7.3 & 7.1 & 5.7 & 5.0 & 4.2 \\
\hline No. of joints involved & 8 & 10 & 11 & 12 & 10 & 3 & 3 & 4 & 6 & 4 & 6 & 17 & 6 & 8 & 13 \\
\hline Small joints (\%) & 22 & 27 & 31 & 49 & 30 & 6 & 9 & 15 & 19 & 21 & 18 & 19 & 19 & 39 & 40 \\
\hline \multicolumn{16}{|l|}{ Upper extremities } \\
\hline Wrists (\%) & 29 & 31 & 39 & 54 & 35 & 10 & 9 & 17 & 23 & 26 & 31 & 15 & 29 & 28 & 40 \\
\hline Shoulders (\%) & 7 & 8 & 22 & 30 & 13 & 2 & 0 & 2 & 4 & 6 & 15 & 15 & 14 & 11 & 40 \\
\hline \multicolumn{16}{|l|}{ Lower extremities } \\
\hline Hips (\%) & 2 & 10 & 28 & 35 & 13 & 3 & 5 & 9 & 4 & 9 & 15 & 19 & 24 & 33 & 33 \\
\hline Knees (\%) & 44 & 31 & 35 & 49 & 30 & 38 & 15 & 32 & 28 & 24 & 23 & 23 & 29 & 28 & 40 \\
\hline Cervical spine $(\%)$ & 2 & 6 & 11 & 32 & 13 & 2 & 0 & 3 & 9 & 9 & 8 & 12 & 0 & 6 & 13 \\
\hline $\begin{array}{l}\text { Cumulative no. of } \\
\text { joints }\end{array}$ & 12 & 17 & 20 & 28 & 25 & 3 & 6 & 7 & 8 & 9 & 6 & 13 & 16 & 17 & 21 \\
\hline
\end{tabular}

Frequency of clinical characteristics. Tables 2 and 3 summarize the frequency of clinical and laboratory characteristics of the children with JRA, according to onset type. For convenience, only data at followup times of $1 / 2,3,5,7$, and 10 years are shown. There were too few children evaluated at 15 years for that time point to be included. The variation in the number of children at each interval reflects the fact that additional children were being entered into the study as it progressed, and other children were lost to followup. Based on this compilation of cases, conclusions from this criteria study reflect predominantly cross-sectional analysis and not sequential followup of single cases.

Polyarthritis. SCAT seropositivity in relation to clinical features of the disease was assessed for children with polyarthritis versus those with oligoarthritis; results of these comparisons are shown in Table 4. Sixteen children with polyarthritis and 9 with oligoarthritis were SCAT-positive. In each group, the age at disease onset was somewhat older in the seropositive children than in a corresponding group of seronegative patients, and there were more females, a higher percentage of ANA seropositivity, predominant involvement of the small joints of the hands, and a higher frequency of erosions that occurred during the disease course.

Cluster analysis identified the number of joints involved ( 5 or more) as the most important variable associated with outcome (course at 5 years or more) in children with polyarthritis. SCAT positivity was the next most important variable, and beyond that, a weaker identification of female sex as an important variable was made.

Table 3. Characteristics of children with juvenile rheumatoid arthritis, according to disease onset type and disease duration

\begin{tabular}{|c|c|c|c|c|c|c|c|c|c|c|c|c|c|c|c|}
\hline & \multicolumn{5}{|c|}{$\begin{array}{c}\text { Polyarthritis } \\
\text { followup at (years) }\end{array}$} & \multicolumn{5}{|c|}{$\begin{array}{c}\text { Oligoarthritis } \\
\text { followup at (years) }\end{array}$} & \multicolumn{5}{|c|}{$\begin{array}{l}\text { Systemic disease } \\
\text { followup at (years) }\end{array}$} \\
\hline & $1 / 2$ & 3 & 5 & 7 & 10 & $1 / 2$ & 3 & 5 & 7 & 10 & $1 / 2$ & 3 & 5 & 7 & 10 \\
\hline Articular erosions (\%) & 10 & 28 & 69 & 81 & 63 & 6 & 13 & 15 & 18 & 17 & 0 & 25 & 29 & 80 & 60 \\
\hline Functional class & 1.7 & 1.7 & 1.8 & 1.8 & 1.6 & 1.5 & 1.4 & 1.4 & 1.3 & 1.6 & 1.7 & 1.4 & 1.6 & 1.4 & 1.9 \\
\hline Intermittent fever & 0 & 0 & 0 & 0 & 0 & 0 & 0 & 0 & 0 & 0 & 0 & 0 & 0 & 0 & 0 \\
\hline Rheumatoid rash (\%) & 0 & 0 & 0 & 0 & 0 & 0 & 0 & 0 & 0 & 0 & 19 & 0 & 10 & 11 & 7 \\
\hline Lymphadenopathy (\%) & 25 & 41 & 49 & 54 & 46 & 23 & 49 & 55 & 57 & 47 & 54 & 62 & 48 & 44 & 40 \\
\hline Hepatomegaly (\%) & 6 & 6 & 2 & 3 & 13 & 5 & 3 & 0 & 0 & 3 & 4 & 8 & 14 & 11 & 7 \\
\hline Splenomegaly (\%) & 3 & 2 & 0 & 3 & 0 & 5 & 1 & 0 & 0 & 0 & 0 & 0 & $\begin{array}{l}14 \\
10\end{array}$ & 6 & 13 \\
\hline Rheumatoid nodules (\%) & 3 & 8 & 15 & 24 & 21 & 0 & 5 & 8 & 9 & 9 & 4 & 8 & 10 & 11 & 17 \\
\hline Rheumatoid factors $(\%)$ & 4 & 8 & 14 & 11 & 9 & 3 & 1 & 0 & 4 & 7 & 0 & 0 & 0 & 0 & 0 \\
\hline Antinuclear antibodies (\%) & 53 & 42 & 38 & 48 & 42 & 41 & 39 & 30 & 40 & 29 & 5 & 0 & 0 & 0 & 0 \\
\hline
\end{tabular}


Table 4. Selected clinical parameters for children with polyarthritis and oligoarthritis who were SCAT-positive*

\begin{tabular}{|c|c|c|c|c|c|c|}
\hline & \multicolumn{3}{|c|}{ Polyarthritis } & \multicolumn{3}{|c|}{ Oligoarthritis } \\
\hline & $\mathrm{RF}+$ & RF- & $P$ & $\mathrm{RF}+$ & $\mathrm{RF}-$ & $P$ \\
\hline No. of children & 16 & 62 & - & 9 & 112 & - \\
\hline $\begin{array}{l}\text { Age at disease onset (years, } \\
\text { mean) }\end{array}$ & 9.6 & 8.1 & $\mathrm{NC}$ & 8.6 & 6.1 & $\mathrm{NC}$ \\
\hline No. males $(\%)$ & $2(13)$ & $17(27)$ & $\mathrm{NC}$ & $1(11)$ & $32(29)$ & $\mathrm{NC}$ \\
\hline ANA+, n/total (\%) & $15 / 16(94)$ & $23 / 57(40)$ & $<0.01$ & $6 / 9(67)$ & $60 / 109(55)$ & $\mathrm{NC}$ \\
\hline $\begin{array}{l}\text { Hand joints involved, } n / \text { total } \\
(\%)\end{array}$ & $16 / 16(100)$ & $52 / 62(84)$ & $<0.05$ & $9 / 9(100)$ & $49 / 112(44)$ & NC \\
\hline Erosions, n/total (\%) & $12 / 15(80)$ & $28 / 58(48)$ & $<0.05$ & $8 / 9(89)$ & 19/107 (18) & $<0.001$ \\
\hline
\end{tabular}

* SCAT $=$ sheep cell agglutination test $; \mathrm{RF}=$ rheumatoid factor; $\mathrm{NC}=$ statistic not computed because of too few values; ANA = antinuclear antibodies.

Oligoarthritis or pauciarticular onset. Children with oligoarthritis were defined as those developing arthritis in 4 or fewer joints. Oligoarthritis was predominantly a disease of the lower extremities. Joints of the lower extremities were involved in $90 \%$ of the children at disease onset. Even after 10 years of followup, only $26 \%$ of these children had upper extremity involvement.

Children with oligoarthritis might have an oligoarthric disease course, develop polyarthritis, or continue with a single joint involved (monarthritis). Except for the number of joints involved, the only important variable that correlated with disease course was functional class, which tended to be poorer in those children with a polyarthric course. Numbers of erosions were similar in all oligoarthric groups at the longer followup intervals.

Two subsets of JRA patients were identified under this onset type. The first included young girls who were ANA-positive and either had or developed chronic uveitis (iridocyclitis) (17 of 121, 14\%). The characteristics of this group were striking throughout the course of the disease. Cluster analysis identified the lack of involvement of the wrists, female sex, ANA positivity, and involvement of the joints of the lower extremities as important characteristics in defining this subset. This group showed little change in type of arthritis during the course of the disease. A second group of children was identified; they were SCAT-positive and had a disease course characteristic of polyarthritis (9 of $121,5 \%$ ). Cluster analysis confirmed that wrist involvement was frequent, erosions tended to develop early, and iridocyclitis occurred infrequently.

Additional observation is required to classify the other children in this onset type; however, a group of SCAT-negative children was identified (12 of $121,9 \%$ ), and these children tended to be boys who were older at disease onset and were B27-positive. Outcome analysis of these children at a mean disease duration of 7 years indicated that there was no clinical or radiologic identification of disease in their hips, shoulders, or sacroiliac joints. In many of the remaining children with oligoarthric onset, the disease remained persistently pauciarticular.

Systemic onset. Children with systemic onset JRA were defined as those who displayed a daily or twice-daily intermittent fever for at least 2 weeks. By 2-5 years after disease onset, systemic manifestations such as pericarditis had subsided, and the course of the disease thereafter was predominantly related to the number of joints involved: either polyarthritis or oligoarthritis. Erosions developed in $45 \%$ of these children, and in $25 \%$ of the group, functional class deteriorated during the course of the disease. Development of a typical JRA rash was limited to children in this group.

Two subsets of JRA were identified in children with systemic disease. At disease onset, 25 of 28 children (early-entry group) had 4 or fewer joints involved (oligoarthritis). This onset subtype was associated with a favorable outcome. Three of 28 children had involvement of 5 or more joints. These latter children had a course typical of polyarthritis, with a poorer outcome. It is important to note that results of serologic studies (SCAT and ANA) were almost invariably negative in children with systemic onset disease, irrespective of the number of joints involved at onset or during the course of the disease.

Children with systemic onset disease who had oligoarthritis at onset were compared with those children who presented with systemic disease and polyar- 
Table 5. Course of juvenile rheumatoid arthritis in children with systernic onset with oligoarthritis versus those with oligoarthritis without systemic onset*

\begin{tabular}{lccc}
\hline & $\begin{array}{c}\text { Systemic } \\
\text { onset with } \\
\text { oligoarthritis }\end{array}$ & $\begin{array}{c}\text { Oligoarthritis } \\
\text { without } \\
\text { systemic } \\
\text { onset }\end{array}$ & $P$ \\
\hline $\begin{array}{l}\text { No. males/total } \\
\quad \% \text { male) }\end{array}$ & $17 / 30(57)$ & $18 / 43(42)$ & $\mathrm{NC}$ \\
$\begin{array}{l}\text { Age at disease onset } \\
\quad(\text { years, mean) }\end{array}$ & 4.8 & 7.6 & $\mathrm{NC}$ \\
$\begin{array}{l}\text { Duration (years, mean) } \\
\text { Erosions (\%) }\end{array}$ & 2.6 & 1.6 & $\mathrm{NC}$ \\
$\begin{array}{l}\text { Knee joint involvement } \\
(\%)\end{array}$ & 17 & 10 & $<0.01$ \\
$\begin{array}{l}\text { Hip involvement }(\%) \\
\text { Cervical spine ankylosis }\end{array}$ & 25 & 47 & $<0.01$ \\
$(\%)$ & 17 & 3 & $<0.01$ \\
\end{tabular}

* Children with oligoarthritis without systemic onset were those who were sheep cell agglutination test-negative, antinuclear antibody-negative, HLA-B27-negative. $\mathrm{NC}=$ statistic not computed because of too few values.

thritis. The average age at onset (5.7 versus 7.0 years) and the frequency of boys ( $45 \%$ versus $57 \%$ ) were greater in the latter group (statistical analysis not done because of too few values). At the last followup, the presence of active synovitis in all of the children with oligoarthritis was significantly greater than that in the children with systemic onset disease and polyarthritis (11 of 11 versus 29 of 40 , respectively, $P<0.001$ ).

Table 5 displays the characteristics of the disease in 30 children with systemic onset who had oligoarthritis during their disease course, compared with 43 children with SCAT-, ANA-, and B27-negative oligoarthritis who did not have a systemic onset. Variables that reached statistical significance included the greater frequency of erosions, involvement of the hips, and radiographic identification of ankylosis of the cervical spine in the former group, and predominant involvement of the knees in the latter group.

Chronic uveitis. The development of chronic uveitis was analyzed in children with polyarthritis and in those with oligoarthritis in order to confirm the previously reported characteristics of these defined subsets. However, only 4 children with polyarthritis developed chronic uveitis during the course of their disease. In general, children who developed uveitis, irrespective of onset type, tended to be younger at disease onset, female, and ANA-positive.

HLA-B27. Table 6 shows the results of selected variables in 12 children who were B27-positive and presented with oligoarthritis. These children tended to be older at disease onset than the corresponding group
Table 6. Selected clinical parameters in HLA-B27+ children with oligoarthritis*

\begin{tabular}{lccc}
\hline & B27+ & B27- & $P$ \\
\hline No. of children & 12 & 109 & - \\
Age at disease onset (years, mean) & 7.5 & 6.3 & $<0.001$ \\
$\%$ male & 75 & 22 & $<0.01$ \\
SCAT+ $(\%)$ & 0 & 19 & $<0.001$ \\
ANA+ $(\%)$ & 27 & 37 & $\mathrm{NC}$ \\
Wrist involvement (\%) & 33 & 20 & $<0.01$ \\
Erosive arthritis (\%) & 18 & 10 & $<0.001$ \\
SI joint involvement (\%) & 0 & 1 & $\mathrm{NC}$ \\
Chronic uveitis (\%) & 0 & 2 & $\mathrm{NC}$ \\
\hline
\end{tabular}

* SCAT = sheep cell agglutination test; ANA = antinuclear antibodies; $\mathrm{NC}=$ not computed because of too few values. $\mathrm{SI}=$ sacroiliac.

and had a lower frequency of SCAT positivity, more frequent involvement of the wrists, and early development of erosions. The 9 boys who were B27-positive, and who might have been suspected of developing ankylosing spondylitis in the future, were followed clinically and radiologically for an average duration of 7 years. At the end of this period of observation, none of these children had features of juvenile ankylosing spondylitis.

Outcome. Table 7 includes data on the 5-year outcome for the early-entry group of 138 children. These results were not significantly different from those of the late-entry group of children. During the course of disease, defined as the 1/2-year to 4-year

Table 7. Disease course and outcome of the early-entry group (138 children) at 5 years, according to onset type*

\begin{tabular}{lccc}
\hline & $\begin{array}{c}\text { Polyarthric } \\
\text { onset } \\
(\mathrm{n}=48)\end{array}$ & $\begin{array}{c}\text { Oligoarthric } \\
\text { onset } \\
(\mathrm{n}=71)\end{array}$ & $\begin{array}{c}\text { Systemic } \\
\text { onset } \\
(\mathrm{n}=19)\end{array}$ \\
\hline $\begin{array}{l}\text { Disease course } \dagger \\
\text { Remission }\end{array}$ & $15 / 48$ & $12 / 71$ & $9 / 19$ \\
Polyarthric & $26 / 48$ & $18 / 71$ & $5 / 19$ \\
Oligoarthric & $7 / 48$ & $41 / 71$ & $5 / 19$ \\
& & & \\
Disease outcomeł & & & \\
Remission course & $8 / 15$ & $7 / 12$ & $9 / 9$ \\
$\quad$ Continued remission & $0 / 15$ & $3 / 12$ & $0 / 9$ \\
$\quad$ Developed oligoarthritis & $7 / 15$ & $2 / 12$ & $0 / 9$ \\
$\quad$ Developed polyarthritis & & & \\
Polyarthric course & $4 / 26$ & $3 / 18$ & $3 / 5$ \\
$\quad$ Disease remission & $3 / 26$ & $5 / 18$ & $1 / 5$ \\
$\quad$ Became oligoarthric & $19 / 26$ & $10 / 18$ & $1 / 5$ \\
$\quad$ Continued polyarthric & & & \\
Oligoarthric course & $0 / 7$ & $14 / 41$ & $2 / 5$ \\
$\quad$ Disease remission & $5 / 7$ & $23 / 41$ & $2 / 5$ \\
$\quad$ Continued oligoarthric & $5 / 4$ & $1 / 5$ \\
$\quad$ Developed polyarthritis & $2 / 7$ & $4 / 41$ & \\
\hline
\end{tabular}

* Those children who entered the study during the first 6 months of disease.

$\dagger$ From 6 months to 4 years.

\# From year 4 to year 5 . 
interval, 15 children who had a polyarthric onset, 12 with an oligoarthric onset, and 9 with a systemic onset entered disease remission. Of these 3 groups, 8 of 15 children with polyarthritic onset remained in remission; 7 of 12 with oligoarthric onset and 9 of 9 with systemic onset remained in remission. However, 7 of the 15 children with polyarthric onset experienced a subsequent exacerbation, as did 2 of the 12 with a pauciarticular onset.

Twenty-six children with an onset characterized as polyarthritis experienced a polyarthric course. Four of these entered remission, 3 developed oligoarthritis sometime during the course of the disease, and 19 continued with polyarthritis. Eighteen children with pauciarticular onset were in this course subtype. Three of 18 entered remission, 5 continued with an oligoarthric course, and 10 developed polyarthritis. Five children with systemic onset experienced a polyarthric course. Three entered remission, 1 developed oligoarthritis, and 1 continued with polyarthritis. Seven of the 15 children with polyarthritis had an oligoarthric course; 5 of these children remained oligoarthric, whereas 2 became polyarthric during the course of the disease. Fourteen of 41 children with oligoarthritic onset who had an oligoarthric course entered remission, 23 continued with oligoarthritis, and 4 developed polyarthritis. Two of 5 children with systemic onset and an oligoarthric course entered remission, 2 continued with oligoarthritis, and 1 developed polyarthritis.

\section{DISCUSSION}

There exist no uniformly accepted criteria for the various forms of idiopathic inflammatory peripheral arthritis in children. During the past 30 to 40 years, several authors have proposed sets of criteria for these diseases. Bywaters in 1968 (3), Laaksonen in 1970 (4), Ansell in 1978 (5), and Kvien et al in 1982 (6) have reviewed the characteristics of these criteria. In addition to the criteria proposed by this subcommittee of the ARA, criteria by the English $(3,5)$ and the European League Against Rheumatism (EULAR)World Health Organization (WHO) Workshop were compiled in Oslo in 1977 (7).

The term juvenile rheumatoid arthritis, adopted in the 1973 and 1976 criteria, is based upon common usage and has been retained by this subcommittee. Without a better understanding of the etiology or pathogenesis of this group of diseases, we saw little justification for changing a diagnostic term that had been used by physicians in the United States for the past 50 years. Indeed, the reasons for not altering nomenclature at this time were compelling in terms of the status of pediatric rheumatology as an emerging discipline.

These clinical criteria for JRA define the age group of children under discussion, the objective criteria for a diagnosis of arthritis, the duration of disease during the entry period necessary for certainty of diagnosis (i.e., 6 weeks), the 3 types of onset, and the necessity of carefully considering diagnostic exclusions.

The actual percentage of children first diagnosed as having JRA who go on to develop another rheumatic disease during their disease course is not precisely known. The studies by Ansell and colleagues $(8,9)$ have cast some light on this matter. Their classification of juvenile polyarthritis indicates the percentage of children with an initial diagnosis of Still's disease who developed another identifiable rheumatic syndrome during followup. Children originally considered to have Still's disease, as defined by the Taplow (England) group, but not fulfilling their criteria, were labeled in the initial studies as having probable Still's disease. Followup by this same group of investigators has shown that few of these children went on to develop a disease that met the classic criteria for Still's disease.

In a study by Dequeker and Mardjuadi (10), further observations on the long-term course of children with juvenile chronic arthritis have been provided. Only 3 of 96 patients characterized by a high frequency of $\mathrm{B} 27$ positivity ( $52 \%$ ), a relatively late onset of disease, and male predominance were later reclassified as having developed clinical characteristics of spondylarthropathy. None, however, satisfied strict criteria for a diagnosis of ankylosing spondylitis in adults. In that study, HLA-B27 positivity did not appear to be a predictor of the subsequent development of typical ankylosing spondylitis or of eventual functional class. During the long followup period in that study, none of 11 children classified as having spondylarthropathy at disease onset progressed to having a definite diagnosis of ankylosing spondylitis (excluding 3 patients with Reiter's syndrome and 1 with psoriatic arthritis). All continued to have disease principally characterized by peripheral arthritis.

A recent study by Jacobs et al (11) addressed the question of B27 positivity in a group of 58 children seen at Columbia University in New York City. The authors did not indicate in their review how many of 
the children were identified clinically, or could have been identified at onset, as having spondylarthropathy; however, only 10 boys had radiologic sacroiliac arthritis at 5 years, and 3 had the Reiter triad.

Although in the present study, children who were B27-positive, especially boys, tended to have lower extremity arthritis, all children in the Cincinnati database who had oligoarthritis had predominantly lower extremity arthritis, and few developed extensive disease of the upper extremities or cervical spine. Followup clinical and radiologic studies did not confirm an interval development of features of spondylarthropathy. Whether these children will develop those features in the future is, of course, not evident now. This study does not confirm clinical impressions that indicate that B27 seropositivity is associated with the future development of spondylitis.

Based on an analysis of rheumatoid factor seropositivity, it appeared that this variable selected a group of girls who tended to have a later age at onset of disease, with predominantly small joint involvement, and a poorer outcome than did members of comparable groups. However, it should be stressed that these observations have been made on the basis of screening by a slide test and confirmation by sensitized sheep cell agglutination, rather than a latex fixation test. Additionally, rheumatoid factor seropositivity did not always appear in a child at the onset of the disease, and only in retrospect was it a group discriminator. Use of the SCAT failed to identify at disease onset at least one-third of the children who would eventually be seropositive.

Rheumatoid factor-seropositive children with oligoarthritis tended to have much the same profile and outcome as rheumatoid factor-seropositive children with polyarthritis. In this specific analysis it appeared that rheumatoid factor seropositivity was an important prognostic factor, as compared with the number of joints involved at onset of disease. In contrast, however, children with systemic disease who had polyarthritis tended to develop clinical and radiologic features of their arthritis that were very similar to those in children with polyarthritis who were rheumatoid factor-seropositive. In like manner, children with systemic disease who had oligoarthritis tended to develop disease similar to that in children with oligoarthritis who had not experienced a systemic onset. In these cases, the number of joints involved at onset or during the course of the disease, and not rheumatoid factor seropositivity, appeared to be the predominant factor determining outcome.
Antinuclear antibody seropositivity was also examined as a discriminator of disease. In this study, ANA appeared to be associated with children who had polyarthritis or oligoarthritis and were female, younger at onset of disease, and had a lower percentage of erosions.

There were 17 children with oligoarthritis who developed chronic uveitis. In general, they had a very young age at disease onset versus children in other comparable groups, were predominantly girls, had a high frequency of ANA positivity, and a low frequency of erosions. The development of chronic uveitis in children in the Cincinnati database was delimited by the same parameters that had been identified in numerous other studies (12).

\section{CONCLUSIONS}

1. Those children who were initially SCATpositive or became SCAT-positive, whether the onset was polyarthritis or oligoarthritis, were older, included more females, had more ANA seropositivity, had more small joint involvement of the hands, more erosions, and were likely to experience a polyarthric course. SCAT positivity was unusual at any time in children with systemic onset.

2. ANA seropositivity in children with polyarthritis or oligoarthritis was associated with female sex and young age at disease onset. In children with oligoarthritis, chronic uveitis was strongly associated with ANA positivity. ANA positivity was not related to early development of erosions and was unusual at any time in children with systemic onset.

3. HLA-B27 positivity was found in only $9 \%$ of the children in this study. This marker was associated with male sex and an older age at disease onset only in the children with oligoarthric onset. HLA-B27 was found chiefly in children who were SCAT-negative and ANA-negative.

4. Excluding those children with SCAT and ANA positivity, children with polyarthritis were older than those with oligoarthritis, but there was no discernible difference in sex distribution between these 2 groups.

5. In children with oligoarthritis, the knees were the joints most frequently involved, whatever the subsequent course. The fewer the involved joints during the subsequent course of the disease, the more the sex distribution was male-predominant. In this group, involvement of the wrists and proximal interphalangeal joints was absent in those with a monarth- 
ric course, rare in those with an oligoarthric course, and fairly frequent in children with a polyarthric course.

6. Children who developed chronic uveitis were almost exclusively female and younger by at least 3 years than children in a comparable group without uveitis. The ratio of children with oligoarthritis who developed uveitis, compared with those who had polyarthritis, was $3: 1$.

7. Children with systemic onset disease and either polyarthric or oligoarthric courses had the same articular characteristics as their counterparts with SCAT-positive or SCAT-negative oligoarthritis or polyarthritis. Children with systemic disease who experienced a polyarthric course had a relatively younger age at disease onset and more hip disease than did comparable children with polyarthritis. Children with systemic onset disease who experienced an oligoarthric course were younger and were more likely to be male than were those children who had a polyarthric course.

\section{REFERENCES}

1. Brewer EJ Jr, Bass JC, Cassidy JT, Duran BS, Fink CW, Jacobs JC, Markowitz M, Reynolds WE, Schaller J, Stillman JS, Wallace SL: Criteria for the classification of juvenile rheumatoid arthritis. Bull Rheum Dis 23:712-719, 1972

2. Brewer EJ Jr, Bass J, Baum J, Cassidy JT, Fink C, Jacobs J, Hanson V, Levinson JE, Schaller J, Stillman JS: Current proposed revision of JRA criteria. Arthritis Rheum (suppl) 20:195-199, 1977
3. Bywaters EGL: Diagnostic criteria for Still's disease (juvenile RA), Population Studies of the Rheumatic Diseases, Proceedings of the Third International Symposium, New York, June 1966. Edited by PH Bennett, PHN Wood. Amsterdam, Excerpta Medica Foundation, 1968, pp 235-240

4. Laaksonen A-L: Juveniilin reumatoidiartriitin diagnostiset kriteerit. Duodecim 86:333-339, 1970

5. Ansell B: Criteria and classification in the UK, The Care of Rheumatic Children. Edited by E Munthe. Basel, EULAR Publishers, 1978, pp 152-153

6. Kvien TK, Høyeraal HM, Kåss E: Diagnostic criteria of rheumatoid arthritis in children: proposed criteria for controlled clinical studies. Scand J Rheumatol 11: 187-192, 1982

7. Wood PHN: Special meeting on nomenclature and classification of arthritis in children, The Care of Rheumatic Children. Edited by E Munthe. Basel, EULAR Publishers, 1978, pp 47-50

8. Ansell BM, Bywaters EGL: Diagnosis of "probable" Still's disease and its outcome. Ann Rheum Dis.21: 253-262, 1962

9. Ansell BM, Wood PHN: Prognosis in juvenile chronic polyarthritis. Clin Rheum Dis 2:397-407, 1976

10. Dequeker J, Mardjuadi A: Prognostic factors in juvenile chronic arthritis. J Rheumatol 9:909-915, 1982

11. Jacobs JC, Berdon WE, Johnston AD: HLA-B27associated spondyloarthritis and enthesopathy in childhood: clinical, pathologic, and radiologic observations in 58 patients. J Pediatr 100:521-528, 1982

12. Cassidy JT, Sullivan DB, Petty RE: Clinical patterns of chronic iridocyclitis in children with juvenile rheumatoid arthritis. Arthritis Rheum 20:224-227, 1977 